\title{
The role of education in the social reintegration of young offenders and the influence of COVID19 pandemic period
}

\author{
Mihaela Tomita*, Roxana Ungureanu*•
}

\begin{abstract}
The number of young people around the world, sanctioned with an educational measure depriving them of their liberty is increasing, which is also found in the statistics of educational centers in Romania. Custodial measures are those which punish juvenile offenders by depriving them of their liberty after they have been convicted of an offense. By being internment in the center, they are prevented from committing new offenses and, at least in theory, are allowed to be rehabilitated during the period of internment. In the custodial environment, education for minors and young people has been and remains different in many ways from that in the community. In this, beyond the architecture of the custodial environment, the profile of this type of criminals obviously has a significant role. In this paper, we aimed to highlight the particularities of education for minors and young people in the custody environment in general and in educational centers in Romania in particular, and how the pandemic period COVID19 influences programs in educational centers. 27 interviews were applied to professionals from two educational centers in Romania (Buziaş Educational Center and Târgu Ocna Educational Center). The interview guide for professionals and management staff totaled 22 questions. In this paper we have focused only on the questions that refer to the social reintegration of minors and young people interned in the centers. Our analysis shows us that young offenders faces several issues specific to custodial environments to which are added the restrictions imposed by the pandemic period. This restriction takes on specific forms, adapted to the custodial environment. Educators, psychologists, and schoolteachers can play an important role together with parents in social reintegration and defining and establishing their life projects.
\end{abstract}

Keywords: social reintegration, education, young offenders, COVID 19

\footnotetext{
- Professor, PhD, International Center for interdisciplinary research on human rights, West University of Timisoara, E-mail: mihaela.tomita@e-uvt.ro

•• Research assistant, PhD, International Center for interdisciplinary research on human rights, West University of Timisoara, E-mail: roxana.ungureanu@e-uvt.ro
} 


\section{Minors and young tenegers in the criminal justice system in Romania}

In the architecture of the criminal justice system in Romania, minors and young people occupy a special place.

The sanctioning system provided in the current Romanian Criminal Code is a system based exclusively on educational measures. The taking of an educational measure is conditioned by the commission of a crime by a minor who is criminally liable, even if at the time of the trial he had become an adult (he has reached the age of 18).

The educational measures provided by law applicable to juveniles who commit crimes are of two types: non-custodial educational measures (civic training, supervision, weekend registration and daily assistance) and educational measures depriving of liberty (internment in an educational center and internment in a detention center).

The regulation of the sanctioning regime of the minority is one of the matters that have undergone the greatest transformations in the new Criminal Code. An educational measure could be taken against the juvenile who is criminally liable, or a punishment could be applied. The new Criminal Code completely renounces punishments in the case of minors, establishing a sanctioning system based exclusively on educational measures. According to him, a non-custodial educational measure is usually taken against a minor who is criminally liable. An educational measure of deprivation of liberty may be taken against a minor in the following cases: a) if he has committed another crime, for which an educational measure has been applied to him which has been executed or whose execution began before committing the crime for which he is judged; b) when the punishment provided by law for the crime committed is imprisonment of 7 years or more or life imprisonment. Non-custodial educational measures are criminal law sanctions that apply to juveniles who have committed a crime whose seriousness does not require deprivation of liberty. The non-custodial measures are the preferred measures, but the raising numbers of decisions for non-custodial measures does not directly determined a decreasing in custodial ones (Tomiță, Predescu, \& Dârjan, 2017).

The educational measure of internment in an educational center consists in the internment of the minor, for a period between 1 and 3 years, in an institution specialized in the recovery of minors, where he will follow a program of school training and professional training according to his skills, like social reintegration programs.

If during the internment the minor has shown constant interest in acquiring school and professional knowledge and has made obvious progress towards social reintegration, after the execution of at least half of the internment, the court may order: a) to replace the internment with the educational measure of daily assistance for a period equal to the duration of the unexecuted internment, but not more than 6 months, if the internment person has not reached the age of 18; b) release from the educational center, if the internment person has reached the age of 18.

With the replacement or release, the court imposes the observance of one or more obligations until the fulfillment of the duration of the internment measure. To the extent that the minor does not comply, in bad faith, with the conditions of execution of the daily 
assistance measure or the imposed obligations, the court returns to the replacement or release and orders the execution of the remaining unexecuted measure during the measure of internment. The court may order the extension of the duration of the measure, without exceeding the maximum provided by law, or may replace it with the measure of internment in a detention center when: - during the internment the minor commits a new crime or is tried for a concurrent crime previously committed; - after the replacement with daily assistance, the person commits a new crime before reaching the age of 18 . If during the execution of the educational measure the inmate, who has reached the age of 18 , has a behavior that negatively influences or impedes the process of recovery and reintegration of other inmates, the court may order the continuation of the educational measure in a penitentiary.

The educational measure of internment in a detention center consists in the internment of a minor in an institution specialized in the recovery of minors, with a guard and supervision regime, where intensive social reintegration programs will follow, as well as school training and vocational training programs according to their skills. The internment is ordered for a period of between 2 and 5 years, unless the punishment provided by law for the crime committed is imprisonment of 20 years or more or life imprisonment, when the detention is for a period of between 5 and 15 years (file:///C:/Users/01/Downloads/1 FLORIN STRETEANU noul cod penal coment\%20(1).p df).

Decisions about the special conditions, the intensity of supervision or the actual meaning of the control exercised, can have an important impact on the life of the young offender. That is why it is extremely important that in making these decisions, there is an in-depth consultation with probation services, which in turn may seek specialist advice from other service providers (Tomita \& Ungureanu, 2016).

\section{The effects of custodial environment}

Psychological problems caused by detention are much less visible than physical ones, often people deprived of their liberty are unaware of them or realize them later, with the help of professionals in the system.

The effectiveness of imprisonment is analyzed in the light of the results of sociological and psychological studies, which are based on three hypotheses: of a wide range of crimes. a) the prison, as a "school of crime", where the detainees learn, from their cellmates, new techniques and ways of committing a very varied range of crimes. This view argues that some convicts, especially veterans, "train" young people at the beginning of their criminal careers, maintaining or even increasing their interest in this type of activity; b) imprisonment, as a pathological environment, which produces a series of negative effects on the mental health of individuals (problems with self-control, apathy, lethargy, despair, anger); c) prison, as a type of social institution, in which the official aspects, but especially the unofficial ones of the social organization of the prison are determining factors of the behaviors, opinions and beliefs adopted by individuals during 
detention and which can persist even after release. The way in which detainees adapt to this environment influences their concerns: social relations, the activities they value, the importance of privacy, etc., and the ability to cope with the situation becomes prominent in the penitentiary (Рopa, 2019).

Like adults in prisons, minors and young people in educational and detention centers exhibit extremely diverse behaviors, from forms involving social withdrawal to aggression and extreme violence. Deprivation of liberty favors the appearance and development of aggressive behaviors, often totally different from those manifested prior to hospitalization in the center. The causes of these aggressive behaviors can be generated by: the pressure of the closed environment, the appearance of states of despair, the lack or limited contact with the family, communication with the supervision staff and other professionals in the center, education and family patterns, etc.

The educational centers are intended for the re-socialization of minors and young people who have committed criminal acts and to whom the educational measure of internment in such an environment has been applied. These are the stated purpose of defending society from the danger of the proliferation of antisocial acts, in general, and the protection of minors and young people interned, against the factors that would jeopardize the proper development of their personality.

All activities are oriented towards the safety of its beneficiaries and aim at educational and psychosocial support for the realization of a continuous educational process, consisting of schooling, professionalization, education and psychosocial assistance activities that guarantee the balanced training of minors and young people interned in the center. Being well known that giving responsibility to the minors has a positive influence on their social reintegration process, and because the center is equipped with modern utilities, minors can perform household activities, such as: preparing and serving breakfast, self-serving in the dining hall, washing and ironing clothes and linen, cleaning and maintaining cleanliness in their rooms, classes and shops (Tomita, 2013).

In all cases where possible, in order to carry out the educational and therapeutic activities, the family is involved in maintaining or, as the case may be, improving the relationship with it, as well as the community through the partnership between nongovernmental institutions and organizations.

The individualization of the recuperative interventions, of the programs and activities in which the minors and the young people are involved, is realized according to the characteristics of each of them, for a balanced physical and psychosocial development.

According to official data, the general objectives of the educational centers are: the schooling of the interned persons in accordance with the public education system so that, after their release, they can continue their school preparation without difficulties; the professional training of the interned persons in order to form some competencies that will facilitate their access and success on the labor market; educational intervention in 
the perspective of acquiring pro-social attitudes; therapeutic intervention in order to reorganize and balance the personality; the inclusion of the interned persons in valorizing activities, highlighting their resources, in order to obtain positive changes in the self-image; preparing for the release of internees so that their social reintegration would be easy. (http://anp.gov.ro/centrul-educativ-buzias)

As we previously pointed out, minors and young people interned in educational centers benefit from: individualized rehabilitative psycho-social interventions, schooling and professional qualification, educational programs and recreational programs. Recovery intervention refers to the structured set of programs and activities that offer minors and young people different learning opportunities, through which they acquire those life skills that determine their constructive, autonomous and responsible behavior in the community.

Children with special educational needs are one of the target groups for the strategic priority Ensuring everyone's access to education and improving the quality of education. Several specific measures have been taken to support the integration process - including teacher training, support materials and specific legislation.(https://eacea.ec.europa.eu/national-policies/eurydice/content/ specialeducation-needs-provision-within-mainstream-education-56 ro).

The specialized professionals who carry out their activity in the educational centers benefit from specific training so that they can ensure an inclusive educational environment.

The stage preceding the return to the community begins two months before the release, during which the inmate will participate in specific programs for preparation for family, professional and school reintegration.

Before leaving the center, each inmate is given an evaluation report that is a useful tool in the perspective of post-criminal assistance. It includes information on the inmate's expectations prior to release, future plans, identification of support factors for reintegration into society, social risk situations and proposals for probation services at the inmate's home.

\section{Peculiarities of social reintegration of minors and youth}

Young people interned in educational centers face a number of social, economic and personal problems that tend to become obstacles to reintegration into society (Borzycki \& Baldry, 2003; Visher, Winterfield, \& Coggeshall, 2005). Some of these challenges are the result of past experiences of young people and others are directly associated with the consequences of the time spent at the center (Borzycki, 2005). Young people may have a history of social isolation and marginalization, physical or emotional abuse, unemployment and involvement in a lifestyle that has fostered delinquency, starting at an early age.

Many young inmates face several challenges that make it difficult for them to reintegrate into society: poor interpersonal skills, low levels of formal education, 
illiteracy, poor cognitive or emotional functioning and / or lack of financial planning and management skills. There are also some practical challenges that young people face when they are released from educational centers, including finding adequate accommodation with very limited resources, financial management with little or no savings.

The transition from custody to community can be particularly difficult for young people (Dârjan, Tomiță, \& Predescu, 2017).

It is possible that internment itself had several "side effects" (Borzycki, 2005; Borzycki \& Makkai, 2007) on many young people: they may have lost social relationships, family relationships; they may have experienced mental health difficulties or selfdefeating habits and attitudes. Lack of housing can expose young people to the risk of committing other crimes (Arnull, et al., 2007).

The programs offered in the educational centers vary in effectiveness and none of them is completely effective. Interventions can fail because not all young people are immediately treated: lack of willpower, taking responsibility for their actions, or a poor motivation to change can make a big difference (Stephenson and Jamieson, 2006).

The promotion of criminal policies that contribute to the safety of the community, by preventing recidivism, is one of the international concerns, as we have shown above, which remains current, in a period marked by medical, political, economic and social crises, which generate at least as many social tensions. "Now, perhaps more than ever in recent decades, the balance in the functioning of public administrations is sought, the concept of justice acquiring a predominantly social value, in which the treatment of citizens in conditions of respect and dignity for human quality, individual security and equality chances are defining, fundamental elements. In this context, we recall Rule 4 of the United Nations Minimum Rules for the Treatment of Prisoners - known as the Nelson Mandela Rules (2015), which states that: "1. The purpose of the custodial sentence is, first and foremost, to protect society from crime and to reduce recidivism. These purposes can only be achieved if the period of detention is applied to ensure reintegration into society after release. 2. To this end, the penitentiary administration and other competent authorities shall provide studies, vocational training and employment, as well as other appropriate and applicable forms of assistance, including those of a rehabilitative, moral, spiritual, social, medical and sporting nature" (http://anp.gov.ro/revista-de-practicapenitenciara/noutati/strategia-nationala-de-reintegrare-sociala-a-persoanelor-private2020-2024/).

As a member of the European Union, Romania has sought to transpose the relevant international recommendations into domestic policies. The reform of the penitentiary system has been carried out precisely starting from these standards, strategies, recommendations, rules and European and international directives and is materialized through programmatic documents that take into account the national and cultural specifics. Taking advantage of opportunities of any kind as well as openness to the community essentially mark the transformations of the Romanian penitentiary system. 
The experience of implementing the National Strategy for social reintegration of persons deprived of liberty 2015-2019, highlighted both the institutional capacity itself and the communication and inter-institutional cooperation in the field of resocialization and social reintegration of criminally sanctioned persons.

Through the current National Strategy for the social reintegration of persons deprived of liberty 2020-2024, the issue of social reintegration of detainees is demonstrated from the perspective of the ways of organizing, planning and implementing interventions targeting persons sentenced to imprisonment or deprivation of liberty. Consequently, they include all the recuperative and educational interventions applicable in the educational centers.

The new strategy considers the measures implemented in the period 2015-2019 that need to be continued, the development and customization of social support services, available locally, for people returning to the community, at risk of social marginalization, as well as new measures that require to be made during the reference period.

For the period 2020-2024, the strategic target aims at the functional reintegration of persons released from detention, in the family environment, in the community and on the labor market by consolidating, optimizing and developing legal and procedural mechanisms. By implementing the Strategy, respecting reference values, such as: humanism, integrity, professionalism, openness to the community, a coherent system of social reintegration of persons deprived of liberty will be ensured, with institutional involvement and community support, responding multisectoral to the needs of beneficiaries and society.

\section{Method}

The interviews were conducted with professionals from the two educational centers in Romania, namely the Buziaş Educational Center and the Târgu Ocna Educational Center. The application of this method was carried out on a number of 27 professionals, social workers, psychologists, educators, security personnel, but also people with management positions: Director of the Educational Center, head of the socio-educational service, head of the security service.

A number of 10 professionals from the Târgu Ocna Educational Center participated, and another 17 professionals were interviewed from the Buziaș Educational Center.

The semi-structured interview was used to gather information for an in-depth analysis of the elements related to the perception of professionals on educational measures of deprivation of liberty and the activities that take place in the center, and which support the social reintegration of juveniles. The interview guide for professionals and management staff totaled 22 questions (of which some were specific questions only for management staff), specifically on educational deprivation measures applied to juvenile delinquents and young offenders, and their social reintegration.

For the present paper, we have considered only those questions that refer to the education of young people in schools and how it influences their social reintegration. 


\section{The role of education in the social reintegration of minors and young people in the custodial environment}

The penitentiary system in Romania ensures the necessary conditions for the school training of young people interned in educational centers, for the levels of general compulsory education, in accordance with the norms contained in the National Education Law no. $1 / 2011$, with subsequent amendments and completions, and the conditions established in the collaboration protocol between the Ministry of Education and the Ministry of Justice regarding the schooling and professionalization of detainees. The number of course hours is established in compliance with the framework plans developed by the Ministry of Education. In each penitentiary, with the support of the county school inspectorates and of the Bucharest municipality, schools or classes affiliated to the educational institutions outside the place of detention are organized.

Illiterate people and young people have priority in school education activities. Young people have priority in vocational training.

The recovery activity of the interned persons is an individualized one, starting from the assessment of the developmental needs of each person (taking into account the age, health status, family of origin, personality and behavioral characteristics, individual abilities, educational level, causes and motivation that determined the commission of the crime), recorded in a personal evaluation and development file. The educational intervention aims at schooling, qualification, accumulation of knowledge about themselves and others, development of social skills, experimentation of non-conflicting ways of solving their life problems. The intervention is based on Personilised Education Plans. The last phase is a Transition Plan, that occurs before liberation and has the aim of assuring a effective transition to the new status.

The schooling activity of the interned persons is carried out in accordance with the Education Law and is assimilated to the one of special integrated education from the national education system. Terefore, the schools that are functioning inside Educational Centeres are considered special schools, that reflects in a special curriculum and individualization of teaching and training,

The teachers who carry out the schooling activities come from the public education, and the plans and programs on which the instructive-educational process is based are in accordance with the exigencies of the national education system.

The qualification activity of the interned persons, who have exceeded the age of 16, can be achieved both through the courses of the school of arts and crafts, as well as through introductory and qualification courses, based on the Protocol concluded between the National Administration of Penitentiaries and the National Employment Agency of the Labor Force.

The introductory courses include the interns who have graduated from primary education (minimum 4 classes), and the qualification courses, the interns who have graduated from high school or are in the process of graduating. 
The duration of the courses depends on the complexity of the job and is between 3 and 6 months. After graduation, the interns obtain diplomas attesting their professional training, recognized on the labor market and which give the possibility of employment after release from the educational centers. (http://anp.gov.ro/centrul-educativbuzias/despre-noi/).

The last phase is a Transition Plan, that occurs before liberation and has the aim of assuring an effective transition to the new status.

There were three topics that occurred during the interviews:

1. The minors have a distinct profile. Most of them came from disadvantaged families or from a low-income environment. Most of them have developmental challanges, either intellectual, emotional, or social.

2. There is a strong preference for professional activities. The basic education is not so highly regarded by the minors. That could be the result of prior experiences. Also, they oftenly report that they are not perceiving its benefits.

3. There is a strong need for building relations with peers from outside institution. This goal is achieved through different project with partners (NGOs and schools.)

The educational centers support the minors and the young people through the complex educational activities, social assistance and social rehabilitation programs and aim as finality of the developed activities, the following:

- training the ability to reflect on the world, to solve problems based on the relationship of acquired knowledge;

- valuing one's own examples for the purpose of rehabilitation and social reintegration;

- developing the capacity for active integration in different groups: family, professional environment, friends, etc.

- developing the functional competencies essential for school success: communication, critical thinking, decision making;

- formation of personal autonomy.

An important factor in the social reintegration of young offenders is the educational context. Research shows that schooling is an important factor in resilience for teens in general and delinquent teens in particular. In the answers of specialists, it can be seen that more than $50 \%$ of respondents say that the level of education is very important for the adaptation of young people in the center and their social reintegration.

The educational level is directly proportional to the person's attitude and behavior. Most of them have a low intellectual level and that is why an intervention adapted to the needs of each one is needed.

The mission of the professional (educator, social worker, psychologist, etc.) in the field of juvenile justice can be summarized as follows: 
- To detect the socio-educational needs of the people he will take care of and to elaborate an individualized intervention program for each of them, in accordance with the rest of the professionals in the multidisciplinary team.

- Intervene to channel the needs detected through group dynamics or individually, making the person in charge improve your chances of social reintegration.

- To inform the appropriate legal and administrative courts about each case and its evolution.

We consider that education and the social reintegration of young offenders from the educational centers must continue to the point where we can speak of measures that reflect the authentic, autonomous, real life, a universe built on the resources and potential of each young person released from such an educational center (Ungureanu, Tomita, 2021).

\section{The influence of the pandemic on the education and social reintegration of minors and young offenders}

Since March 2020, the European Penitentiary Services have been under tremendous ongoing pressure to manage the impact of COVID-19 on the prison system, including schools, and to keep young people and staff safe. There have been times in most countries when restrictions have been relaxed, but both staff and minors and young interns have continued to take all measures to ensure their health. Young interns still suffer from a lack of reintegration activities and visits to those closed to them. (https://www.europris.org/covid-19-prevention-measures-in-european-prisons/).

Penitentiary systems are recognized as high-risk environments for the transmission of diseases, especially with airborne transmission, as a result of both the origin of persons deprived of their liberty from disadvantaged population groups, with a higher frequency of illnesses and the conditions that favor the spread in the detention units overcrowding, prison mobility, lack of ventilation, HIV infection or tuberculosis, as well as numerous chronic conditions are present in persons deprived of liberty. The management of an epidemiological situation due to an infectious-contagious disease with a high risk of transmission has always been, for the Romanian penitentiary system, a major public health problem. Measures to prevent and manage the ways of transmitting infectious diseases have been frequently implemented in the penitentiary population. The emergence of COVID-19 has once again raised the issue of prisons as an environment conducive to the development of infectious diseases.

"Outbreaks of COVID-19 in detention facilities are important for public health for at least two reasons: first, explosive outbreaks in these areas have the potential to overwhelm health care services in prisons and to require overcrowded specialist units. and, secondly, the fact that, with an estimated 30 million people released from prison each year worldwide, prisons are a vector for the Community transmission of potential 
infections, which will have a disproportionate impact on marginalized communities" (Akiyama, Spaulding, Rich, 2020).

Among the measures imposed at the level of the National Administration of Penitentiaries (ANP) in Romania, we highlight the most relevant, as follows: isolation at home of staff who had direct contact / close contact with people from epidemiological risk areas or who have presented symptoms of respiratory infection, as well as isolation of persons deprived of their liberty falling under the precautionary measures of this type; elaboration and transmission to the subordinated units (penitentiaries, penitentiary hospitals, educational and detention centers) of a psychological guide regarding the maintenance of the emotional balance during the pandemic, complementary to the measures previously ordered on this line of activity; updating the content of the section on the official website, dedicated to informing the members; creation of the "COVID-19" section, on the ANP Internal Portal, for the correct information of all staff, with relevant information for the implementation of related measures (eg legislation, instructions issued by the Ministry of Internal Affairs, Department for Emergency Situations, recommendations of medical institutions such as the National Institute of Public Health, the National Center for Communicable Disease Surveillance, etc.).

People deprived of their liberty in prisons or other places of detention are much more vulnerable to the spread of the disease caused by the new coronavirus (COVID-19) in comperison with the general population due to the conditions of detention in which they live for extended periods of time. Moreover, experience shows that penitentiaries, arrests and other detention facilities where there are crowds of people close to each other, can be sources of infection, amplification and spread of infectious diseases inside and outside penitentiaries. That is why health in prisons is considered part of the public health system. The response to COVID-19 in prisons and other places of detention is particularly challenging.

1. Citizens detained in prisons and other places of detention should be considered as part of the wider public health response to COVID-19, given their vulnerability to infection.

2. Prisons are the epicenter of infectious diseases due to their higher prevalence of infection, higher levels of risk factors for infection, unavoidable close contact in often overcrowded, poorly ventilated areas, unsanitary facilities and poor access to health services. with the civilian population 3. Infections may be transmitted between prisoners, through staff and visitors, between penitentiaries by transfers or relocation / secondment of staff. As such, prisons and other prisons are an integral part of the public health response to coronavirus disease (SARSCoV-2) (Ștefan, Grecu, 2020).

The effect on the educational activities is less dramatic than on te general education systems. The schooling continued as before, based on direct interaction. However, there are two main effects:

1. The general protocol of isolation of those infected determined interruptions in the teaching process. 
2. The interaction with the outside environment was drastically reduced. All the educational project regarding external partners had to stop at various times and that made the education of minors less effective. The lack of activities with outside partners gave the minors a sense of socialization and normalization, the lack of those activities had an emotional and social cost for them.

\section{Conclusions}

The COVID 19 pandemic, the restrictions imposed by it and the effects felt in all the plans, imposed evaluations and adapted interventions, based on the creativity and professionalism of the workers in all fields. Starting from the specificities of the penitentiary system and in particular, of the educational centers, the major challenge was generated by the lack or delay of the appearance of the legislative framework, of the methodologies, application norms and of the necessary procedures. The regulations related to the access to the Internet, specific to the penitentiary environment, have increased the difficulties related to the development of education in the educational centers. The situations that imposed the isolation of the teachers, of the minors and the young inmates and of the educators, limited the face-to-face meetings, and the didactic activity was carried out with difficulty. As we have shown, the identification of punctual solutions and adapted to each minor or young poeple, has been and continue to be a major concern of all staff working in educational centers. Obviously, a consequence of the restrictions imposed at national level, led to the limitation of the access of the beneficiaries of the center to the outings in the community, of the access of the partner institutions and organizations from the community and of the family visits.

Consequently, the adaptation of institutional capacities has been and is focused on reducing the vulnerabilities generated by the COVID 19 pandemic. Thus, the allocated resources must be designed and available to allow the system to recover from systemic and cascading interruption.

In conclusion, even if most of the expectations of professional who are working in the educational centers are to return to the pre-pandemic situation, we can appreciate that a number of useful developments can be an important opportunity to streamline recovery and education in the custody environment.

The specialized educators who deal with young delinquents have the mission of framing them, supporting and guiding them throughout the judicial process in order to develop together with them an educational project aimed at social, school and / or professional reintegration; restoring the relations between the young man, his family and society; the implementation of educational measures and the execution of court decisions regarding the young person. These skills may exist, but sometimes need to be questioned throughout your professional life. The realization of a training curriculum is part of the efforts to provide quality and means starting from a dynamic and constructive reflection on what is useful to the young person, the organization in which he works, as well as to achieve social expectations. 
Finally, we consider that a new perspective of the organizational culture specific to the custodial environment, can find resources precisely starting from this period of challenges, based on the identified needs and solutions.

\section{References}

Akiyama M.J., Spaulding A.C., \& Rich J.D. (2020). Flattening the Curve for Incarcerated Populations - Covid19 in Jails and Prisons. N Engl J Med. 382(22), pp. 2075-2077.

Arnull, E., Eagle, S., Gammampila, A., Patel, S.L., \& Sadler, J. (2007). Housing Needs and Experiences. London, UK: Youth Justice Board for England and Wales.

Borzycki, M. (2005). Interventions for Prisoners Returning to the Community. A Report Prepared by the Australian Institute of Criminology for the Community Safety and Justice Branch of the Australian Government Attorney General's Department. Canberra: Australian Institute of Criminology. Retrieved from http://www.aic.gov.au/publications/reports/2005-03-prisoners.html 3

Borzycki, M., \& Baldry, E. (2003). Promoting Integration: The Provision of Prisoner Post-release Services. Trends and Issues in Crime and Criminal Justice, 262, Canberra: Australian Institute of Criminology. Retrieved from http://www.aic.gov.au/publications/tandi2/tandi262.html

Borzycki, M., \& Makkai, T. (2007). Prisoner reintegration Post-release, Canberra: Australian Institute of Criminology.

Darjan, I.; Predescu, M. \& Tomita, M. (2017). Mass supervision in school context, in Tomita, M. (2017) Multidisciplinary perspectives in the quasi-coercive treatment of offenders. Mass Supervision, Bologna: Filodiritto Editore - Proceedings, ISBN 978-88-95922-99-7, p. 23-30.

Popa, E. (2019). The unseen part of the penitenciary environment, Journal of Penitentiary Practice No 1/2019; pp. 14-18.

Stephenson, M., \& Jamieson, J. (2006). Barriers to Engagement in Education, Training and Employment. London, UK: Youth Justice Board for England and Wales.

Stefan, L., \& Grecu, R. (2020). The challenge of COVID-19 in the Romanian penitentiary system, Journal of Penitentiary Practice No. 3/2020; pp. 4-12 National Administration of Penitentiaries.

Tomita, M.; Predescu, M.; Darjan, I. (2017). Are the Community Sanctions and Measures the Key for Reducing the Prison Overcrowding? in Tomita, M. (2017) Multidisciplinary perspectives in the quasicoercive treatment of offenders. Mass Supervision, Bologna: Filodiritto Editore - Proceedings, ISBN 97888-95922-99-7. p. 94-100.

Tomiță, M. (2013). Comparative Analysis of Juvenile Delinquency and Non Delinquency. The 3rd World Conference on Psychology, Counseling and Guidance, Procedia - Social and Behavioral Sciences, Vol. 84, pp. 1138-1142, http://www.sciencedirect.com/science/article/pii/S1877042813017898

Tomita, M. A., \& Ungureanu, R. (2016). National regulations on the custodial and non-custodial correctional measures applied to juvenile delinquents, in the Volume „Devianță și criminalitate-evoluție, tendințe și perspective" (Deviance and Criminality-Evolution, Tendencies and Perspectives). Universul Juridic Publishing Company, Bucharest, 74-81.

Ungureanu, R., \& Tomita, M. (2021). The resilience of youth delinquent. Education as a protective factor. Technium Social Sciences Journal, 26(1), 742-748. https://doi.org/10.47577/tssj.v26i1.5289

Visher, C. A., Winterfield, L., Coggeshall, M.B. (2005). Ex-offender Employment Programs and Recidivism: A Meta-analysis, Journal of Experimental Criminology, 1(3), 295-315.

file://C:/Users/01/Downloads/1 FLORIN STRETEANU noul cod penal coment\%20(1).pdf

https://www.europris.org/covid-19-prevention-measures-in-european-prisons/

http://anp.gov.ro/centrul-educativ-buzias/despre-noi/

http://anp.gov.ro/revista-de-practica-penitenciara/noutati/strategia-nationala-de-reintegrare-sociala-apersoanelor-private-2020-2024/ 
https://eacea.ec.europa.eu/national-policies/eurydice/content/special-education-needs-provisionwithin-mainstream-education-56 ro

http://anp.gov.ro/centrul-educativ-buzias 